\title{
A Note on Reviving the Goddard Satellite-Based Surface Turbulent Fluxes (GSSTF) Dataset
}

\author{
Chung-Lin SHIE ${ }^{* 1,2}$, Long S. CHIU ${ }^{3,4}$, Robert ADLER ${ }^{2,5}$, Eric NELKIN ${ }^{2,6}$, I-I LIN ${ }^{7}$, Pingping XIE ${ }^{8}$ \\ Feng-Chin WANG ${ }^{9}$, R. CHOKNGAMWONG ${ }^{3}$, William OLSON ${ }^{2,10}$, and D. Allen CHU ${ }^{1,11}$ \\ ${ }^{1} U M B C / G E S T$, Baltimore, Maryland, USA \\ ${ }^{2}$ Code 613.1, NASA/GSFC, Greenbelt, Maryland, USA \\ ${ }^{3}$ GMU/CEOSR, Fairfax, Virginia, USA \\ ${ }^{4}$ CUHK/ISEIS, Shatin NT, Hong Kong \\ ${ }^{5}$ UMCP/ESSIC, College Park, Maryland, USA \\ ${ }^{6}$ SSAI, Lanham, Maryland, USA \\ ${ }^{7}$ NTU, Taipei, Taiwan \\ ${ }^{8}$ NOAA/CPC, Camp Springs, Maryland, USA \\ ${ }^{9} \mathrm{CWB}$, Taipei, Chinese Taiwan \\ ${ }^{10}$ UMBC/JCET, Baltimore, Maryland, USA \\ ${ }^{11}$ Code 613.2, NASA/GSFC, Greenbelt, Maryland, USA
}

(Received 8 September 2008; revised 24 January 2009)

\begin{abstract}
Accurate sea surface flux measurements are crucial for understanding the global water and energy cycles. The oceanic evaporation, which is a major component of the global oceanic fresh water flux, is useful for predicting oceanic circulation and transport. The global Goddard Satellite-based Surface Turbulent Fluxes Version-2 (GSSTF2; July 1987-December 2000) dateset that was officially released in 2001 has been widely used by scientific community for global energy and water cycle research, and regional and short period data analyses. We have recently been funded by NASA to resume processing the GSSTF dataset with an objective of continually producing a uniform dataset of sea surface turbulent fluxes, derived from remote sensing data. The dataset is to be reprocessed and brought up-to-date (GSSTF2b) using improved input datasets such as a recently upgraded NCEP/DOE sea surface temperature reanalysis, and an upgraded surface wind and microwave brightness temperature V6 dataset (Version 6) from the Special Sensor Microwave Imager (SSM/I) produced by Remote Sensing Systems (RSS). A second new product (GSSTF3) is further proposed with a finer temporal $(12-\mathrm{h})$ and spatial $\left(0.25^{\circ} \times 0.25^{\circ}\right)$ resolution. GSSTF2b (July 1987-December 2008) and GSSTF3 (July 1999-December 2009) will be released for the research community to use by late 2009 and early 2011, respectively.
\end{abstract}

Key words: surface turbulent fluxes, global, oceanic, satellite-based

Citation: Shie, C.-L., L. S. Chiu, R. Adler, E. Nelkin, I-I. Lin, P. Xie, F.-C. Wang, R. Chokngamwong, W. Olson, and D. A. Chu, 2009: A Note on reviving the goddard satellite-based surface turbulent fluxes (GSSTF) dataset. Adv. Atmos. Sci., 26(6), 1071-1080, doi: 10.1007/s00376-009-8138-z.

\section{Introduction}

The Earth's climate is characterized by a myriad of processes that couple the ocean, land, and atmo- sphere systems. The global water cycle's provision of water to terrestrial storage, reservoirs, and rivers rests upon the global excess of evaporation to precipitation over the oceans. Variations in the magni-

\footnotetext{
${ }^{*}$ Corresponding author: Chung-Lin SHIE, Chung-Lin.Shie-1@nasa.gov
} 
tude of this ocean evaporation excess will ultimately lead to variations in the amount of freshwater that is transported (by the atmosphere) and precipitated over continental regions. The air-sea fluxes of momentum, radiation, and freshwater (precipitation-evaporation) play a very essential role in a wide variety of atmospheric and oceanic problems. Information on these fluxes is crucial in understanding the interactions between the atmosphere and oceans, global energy, and water cycle variability, and in improving model simulations of climate variations. These fluxes are thus required for driving ocean models and validating coupled ocean-atmosphere global models. Surface measurements of these fluxes are scarce in both space and time, especially over the oceans and in remote land areas. The Comprehensive Ocean-Atmosphere Data Set (COADS) has collected the most complete surface marine observations since 1854, mainly from merchant ships (Woodruff et al., 1993) . However, the air-sea fluxes and input variables based on COADS have serious spatial and temporal sampling problems plus measurement uncertainty (e.g., da Silva et al., 1994; Josey et al., 1999; Wang and Mcphaden, 2001). It is, therefore, desirable that long-term global datasets of these fluxes be derived either from satellite observations or general circulation models (GCMs). Indeed, satellite measurements nicely complement conventional data to provide or improve space/time estimates of many hydrologic parameters. Several efforts have been made to prepare datasets of ocean surface turbulent fluxes from satellite observations using bulk flux models. The $\mathrm{SSM} / \mathrm{I}$ on board a series of Defense Meteorological Satellite Program (DMSP) satellites spacecraft has provided global radiance measurements for sensing the atmosphere and the surface. A number of techniques have been developed to derive the turbulent fluxes using parameters such as the surface air humidity and winds inferred from the SSM/I radiances (e.g., Chou et al., 1997; Schulz et al., 1997; Curry et al., 1999; Kubota et al., 2002).

Currently, there are several global datasets of ocean surface turbulent fluxes available, which are based on the SSM/I-retrieved surface air humidity and winds. The Hamburg Ocean-Atmosphere Parameters and Fluxes from Satellite Data (HOAPS) has provided pentad and monthly turbulent heat fluxes over the global oceans with a $1^{\circ}$ spatial (latitude-longitude) resolution for the period July 1987-December 1998, based on the method of Schulz et al. (1997). The Goddard Satellite-based Surface Turbulent Fluxes (GSSTF) dataset has two versions of global flux products derived from the SSM/I radiances. Version 1 (GSSTF1) has daily and monthly fields for July 1987December 1994 with a spatial resolution of $2.0^{\circ} \times 2.5^{\circ}$ latitude-longitude (Chou et al., 1997, 2000). Version 2 (GSSTF2) has daily and monthly fields for July $1987-$ December 2000 with a $1^{\circ}$ resolution (Chou et al., 2001), based on the method of Chou et al. (1997) with some improvements (Chou et al., 2003). The Japanese Ocean Flux Dataset with Use of Remote Sensing Observations (J-OFURO) has provided monthly turbulent heat fluxes over the global oceans with a $1^{\circ}$ resolution (latitude-longitude) for 1991-95 (Kubota et al., 2002). These four, along with other flux datasets, have been distributed to the SEAFLUX [i.e., a sea surface turbulent flux project established by the WCRP/GEWEX (World Climate Research Program/Global Energy and Water Experiment) Radiation Panel] Web site for intercomparison studies of ocean surface turbulent fluxes (momentum, latent heat, and sensible heat), flux models, and input parameters used for the derivation of turbulent fluxes conducted by Curry et al. (2004).

Chou et al. (2003) performed validations on both the GSSTF2 data and the bulk flux model that produced the data. The GSSTF2 bulk flux model was tested by using hourly measurements of turbulent fluxes and input parameters of 10 field experiments conducted by NOAA/Environmental Technology Laboratory (ETL) research ships over the tropical and midlatitude oceans during 1991-99 (Fairall et al., 2003; Brunke et al., 2003). Overall, the testing results suggested that the GSSTF2 flux model was generally accurate for weak and moderate winds, but slightly underestimated the latent heat flux (LHF) and sensible heat flux (SHF) for strong winds. Zonal averages of GSSTF2 latent heat fluxes and input parameters over the global oceans during 1992-93 were compared with those of GSSTF1, HOAPS, and the National Centers for Environmental Prediction-National Center for Atmospheric Research (NCEP-NCAR) reanalysis (Kalnay et al., 1996), and da Silva et al. (1994). The large-scale patterns of the GSSTF2 2-yr-mean field for these variables are qualitatively similar to those of the other four datasets. However, these datasets had significant quantitative differences in these variables with GSSTF2, except GSSTF1. For GSSTF1, the differences with GSSTF2 were generally negligibly small for the input parameters, but not for LHF. Averaging the LHF over the ocean within $60^{0} \mathrm{~N}-60^{0} \mathrm{~S}$, the GSSTF1 was $12.7 \mathrm{~W} \mathrm{~m}^{-2}$ larger ( $12 \%$ of the global averaged LHF of GSSTF2) than GSSTF2. In summary, Chou et al. (2003) suggested that the GSSTF2 LHF, surface air humidity, and winds were likely to be more realistic than the other four flux products examined, although those of GSSTF2 were still subject to regional biases. A more detailed regional validation requires more high-quality observations over the global oceans. 
In a follow-up study, with a strict height adjustment for both surface air humidity and wind speeds, Chou et al. (2004) reached a conclusion that was consistent with the simple zonal average analysis of Chou et al. (2003). The global distributions of 1988-2000 annual- and seasonal-mean GSSTF2 turbulent fluxes also showed reasonable patterns related to the atmospheric general circulation and seasonal variations. Accordingly, the GSSTF2 dataset provided a consistent description of the global hydrologic cycle. In addition to its more realistic representations of LHF and surface air humidity than the other four flux products (as aforementioned), the GSSTF2 dataset had the longest (at the time) temporal coverage (July 1987December 2000) over the global oceans with a $1^{\circ}$ fine resolution. This dataset has been widely used by scientific communities for global energy and water cycle research and regional and short period data analysis since its official release in 2001 by NASA/GSFC Data Information Service Center (DISC). However, the GSSTF2 production project ended during 2001.

In a thorough SEAFLUX intercomparison study, Curry et al. (2004) raised several crucial issues for the SEAFLUX communities on their ongoing/future ocean surface turbulent flux productions and studies. These issues include producing high-resolution surface fluxes using combined satellites, improving the quality (and using proper quantity) of the input quantities and parameters for surface flux calculations (i.e., SST, the surface wind field in both magnitude and vector, and the associated high wind coefficients, etc.), and improving the temporal scale (e.g., from daily to $12-\mathrm{h}$ ) of the flux data to accommodate the need for high-frequency interactions between the ocean and the atmosphere. The surface wind speed used in the GSSTF2 production was the SSM/I Version 4 (V4) product by Frank Wentz of RSS. Xing (2006) found a linear trend of a $6 \%$ increase in the associated 13.5-year (July 1987-December 2000) period of the wind data. However, in the most recently issued SSM/I Version 6 (V6) product, Wentz indicated that spurious trends in their wind speed retrievals were removed (details can be found at http://www.ssmi.com).

Therefore, we recently proposed to resume forward processing and complete reprocessing of the GSSTF dataset with a higher spatial resolution using trend-removed SSM/I data, improved sea surface temperature and wind fields (both speeds and vectors) in response to a NASA research announcement. Fortunately, this proposal has recently been funded by NASA. The proposed GSSTF production consists of two phases: (1) reprocessing/extension of the $1^{\circ} \times 1^{\circ}$ (latitude-longitude) GSSTF2b (Version$2 \mathrm{~b}$, first-phase) dataset over the global oceans for a 21.5-yr period from July 1987 to December 2008 using the improved SSM/I V6 (Wentz/RSS) surface wind and microwave brightness temperature data, the recently released NCEP SST reanalysis, and (2) production of a further improved GSSTF3 (Version-3, second-phase) dataset with a revised transfer coefficient setup (accommodating high wind conditions), a finer spatial resolution $\left(0.25^{\circ} \times 0.25^{\circ}\right)$ using the sea surface temperatures from AMSR-E and TMI, and ocean surface wind vectors from QuikSCAT and ADEOS2SeaWinds, over the global oceans for the period July 1999-December 2009.

In addition to a general review of GSSTF2 presented above in this section, a handful of scientific studies and applications of GSSTF2 are described in section 2 . Section 3 addresses justifications and improvements involving the revival of GSSTF production. Section 4 describes the current ongoing and planned productions.

\section{Scientific studies and applications of GSS- TF2}

GSSTF2 has been widely used by scientific communities for global energy and water cycle research, and regional and short period data analysis since its official release in 2001 by NASA/GSFC DISC. Our records (based on personal communications alone) indicate more than 30 communities have been using GSSTF2 for scientific research during the past seven to eight years (2001-2008), not to mention the SEAFLUX Project (Curry et al., 2004) and those who attained GSSTF2 directly from the DISC website. Numerous GSSTF2 (and GSSTF1)-related research studies have been published in journals or presented at conference meetings. The users/authors range from US government agencies (e.g., NASA/GSFC, GISS, LRC, MSFC, and NOAA) to universities and institutes from various countries (e.g., Colorado State University, Columbia University, George Mason University, IAP/Chinese Academy of Sciences, MIT, NTU, UMBC, University of Maryland at College Park, University of Tokai/Japan, University of Washington, Woods Hole Ocean Institution). The datasets were used for various scientific objectives. A few studies are briefly addressed as follows.

Bourras (2005) performed an intercomparison study on five satellite-derived latent heat flux products, i.e., HOAPS-2, J-OFURO, Jones (Jones et al., 1999), GSSTF2, and BEL (Bourras et al., 2002), by comparing them with bulk fluxes calculated with data from 75 moored buoys. Advantages and drawbacks were found among these five fluxes; however, GSSTF2 had the best performance in rms compared to the Na- 
tional Data Buoy Center (NDBC) buoy fluxes. Chiu and Xing (2004) performed an EOF analysis on the GSSTF2 latent heat flux (focusing on the areas between $65^{\circ} \mathrm{N}$ and $65^{\circ} \mathrm{S}$ ) and found two significant and distinct modes of non-seasonal variability. The first EOF, explaining $9.2 \%$ of the total variance, showed a pattern that was consistent with an enhanced Hadley and Walker Circulation. The second EOF, contributing $5.7 \%$ to the total variance, had a clear dipole structure with the positive center located over the western and central Pacific while the negative center was located over the southwestern Pacific. Time series of this second EOF correlated highly with the Southern Oscillation Index (SOI). Both the spatial and temporal variations genuinely suggested that it was an ENSO mode. The GSSTF2 latent heat flux was also chosen as "observations" for validating the global latent heat flux of NCEP CDAS2 (Kanamitsu et al., 2002, a modified version of the widely used NCEP CDAS, Kalnay et al., 1996). Xie et al. (2007) found that a 13-year (1988-2000) annual mean NCEP CDAS2 LHF captured the overall structure of the global evaporation shown in the satellite-based GSSTF2. However, CDAS2 tended to overestimate/underestimate evaporation over the western Pacific \& Indian Ocean/the eastern Pacific \& Southern Ocean. The corresponding global distribution of the annual mean E-P flux (evaporation minus precipitation) was also examined, as the NCEP CDAS2 precipitation was included. An excessive E-P in NCEP Reanalysis 2 (R2) was found against "observation" (based on GSSTF) over the eastern Indian Ocean and western Pacific Ocean, but a deficient E-P in R2 was found over the central Pacific Ocean and high-latitude oceans.

\section{Justifications and improvements}

The bulk flux model (based on the surface layer similarity theory, Chou, 1993) used for performing the current ongoing/future production (GSSTF2b/GSSTF3) is essentially the same as that for GSSTF2 (Chou et al., 2003) except for an improvement in the bulk transfer coefficients for a high wind scenario (see a detailed discussion below) for GSSTF3. Similar to GSSTF2, GSSTF2b and GSSTF3 require the same methodology and same kinds of input data such as the surface/10-m wind speeds $(U)$, total precipitable water $(\mathrm{W})$, bottom-layer $(500 \mathrm{~m})$ precipitable water (WB), SST, 2-m air temperature $\left(T_{\mathrm{a}}\right)$, and sea level pressure (SLP). The daily $1^{\circ}$ GSSTF2 turbulent fluxes were derived from the SSM/I surface winds and surface air humidity, as well as the 2-m air and sea surface temperatures of the NCEP-NCAR reanalysis, using a bulk aerodynamic algorithm based on the sur- face layer similarity theory.

The bulk flux model is currently under testing for applying a more sophisticated setup of transfer coefficients, particularly concerning a high wind scenario. Transfer coefficients, which reflect efficiency of the vertical transportation of momentum, heat, and moisture flux, are a non-linear function of the vertical gradient in wind speed, temperature, and water vapor near the surface, and hence are affected by the stability of the surface air. The GSSTF2 neutral transfer coefficients (at a 10-m height) for wind stress, SHF, and LHF are $1.02 \times 10^{-3}-1.81 \times 10^{-3}, 1.01 \times 10^{-3}-1.18 \times 10^{-3}$, and $1.05 \times 10^{-3}-1.22 \times 10^{-3}$, respectively, for the $10-\mathrm{m}$ wind of $3-18 \mathrm{~m} \mathrm{~s}^{-1}$. The coefficients increase with decreasing wind when the $10-\mathrm{m}$ winds are less than $3 \mathrm{~m} \mathrm{~s}^{-1}$. The GSSTF2 transfer coefficients (for 10-m winds up to $<18 \mathrm{~m} \mathrm{~s}^{-1}$ ) are in close agreement with those of Zeng et al. (1998), Fairall et al. (1996), and Renfrew et al. (2002). Liu et al. (1979) performed a detailed analysis of the transfer coefficients and predicted that under low wind conditions the transfer coefficient might increase with an increasing wind speed since the increased roughness facilitated the transfer of heat and vapor. However, as the wind speed increases further, the sheltering effect due to the troughs between waves becomes more significant and will suppress the exchange of vapor and heat. As the wind speed reaches about $5 \mathrm{~m} \mathrm{~s}^{-1}$, the negative and positive effects due to the increased wind speed counterbalance each other. The transfer coefficient may start to decrease, should the wind speed increase further. Andreas (1992) and Andreas et al. (1995) suggested that at a wind speed of $20 \mathrm{~m} \mathrm{~s}^{-1}$, the latent heat flux due to spray is of a similar magnitude to the turbulent flux. The latest field and laboratory measurements also showed that the drag coefficient did not increase with wind speeds at extreme wind conditions, i.e., greater than $30 \mathrm{~m}$ $\mathrm{s}^{-1}$ (Powell et al., 2003; Donelan et al., 2004). Therefore, high-wind transfer coefficients (based on Powell et al., 2003; Donelan et al., 2004; Black et al., 2007) may be applied for the $10-\mathrm{m}$ winds beyond $18 \mathrm{~m} \mathrm{~s}^{-1}$ in the production of GSSTF3. Such an adjustment for a high-wind scenario should improve the current surface flux retrieval, as well as provide a better understanding of weather systems involving high winds such as tropical cyclones and hurricanes/typhoons. The heat exchange of the upper ocean layer under the core of a hurricane was found to be a critical factor affecting the intensity of tropical cyclones (Emanuel, 1999).

The input parameters required for deriving the GSSTF2b and GSSTF3 turbulent fluxes are essentially the same as those for producing GSSTF2 (Chou et al., 2003). The input datasets used to derive the daily surface turbulent fluxes using the GSSTF2 bulk flux 
Table 1. Characteristics of input data and parameters for GSSTF2, GSSTF2b, and GSSTF3.

\begin{tabular}{|c|c|c|c|}
\hline & \multicolumn{3}{|c|}{ Datasets } \\
\hline & GSSTF2 & GSSTF2b & GSSTF3 \\
\hline$C_{\mathrm{E}}($ transfer coefficient $)$ & Chou (1993) & Chou (1993) & $\mathrm{PDB}^{\mathrm{a}}$ (high wind) \\
\hline $\mathbf{U}$ (speed) & Wentz V4 (1997) & Wentz V6 (2006) & Wentz V6 (2006) \\
\hline$U$ (vector) & Atlas et al. (1996) & $\begin{array}{l}\text { CCMP Level-2.5 } \\
\text { (SSM/I, TMI, and AMSR-E) }\end{array}$ & $\begin{array}{l}\text { CCMP Level-3 (SSM/I, } \\
\text { TMI, AMSR-E, } \\
\text { and QuikSCAT/ADEOS2 } \\
\text {-Sea Winds) }\end{array}$ \\
\hline $\mathrm{W} / \mathrm{WB}$ & Wentz V4 (1997) & Wentz V6 (2006) & Wentz V6 (2006) \\
\hline SST & $\begin{array}{l}\text { NCEP Reanalysis (VI) } \\
\text { Reynolds and Smith (1994) }\end{array}$ & $\begin{array}{l}\text { NCEP Reanalysis (V2) } \\
\text { Reynolds et al. (2002) }\end{array}$ & AMSR-E \& TMI \\
\hline$Q_{10 \mathrm{~m}}$ & Chou et al. $(1995,1997)$ & Chou et al. $(1995,1997)$ & Chou et al. $(1995,1997)$ \\
\hline$T_{\mathrm{a}} / \mathrm{SLP}$ & NCEP & NCEP & NCEP \\
\hline Spatial resolution & $1^{\circ} \times 1^{\circ}$ & $1^{\circ} \times 1^{\circ}$ & $0.25^{\circ} \times 0.25^{\circ}$ \\
\hline Spatial coverage & Global Oceans & Global Oceans & "Global Oceans" b \\
\hline Temporal resolution & Daily and monthly & Daily and monthly & 12-h and monthly \\
\hline Temporal coverage & Jul 1987-Dec 2000 & Jul 1987-Dec 2008 & Jul 1999-Dec 2009 \\
\hline
\end{tabular}

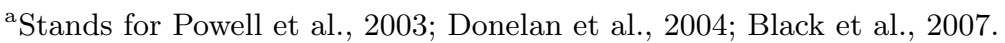

${ }^{\mathrm{b}}$ Likely a smaller domain than $90^{\circ} \mathrm{N}-90^{\circ} \mathrm{S}$.

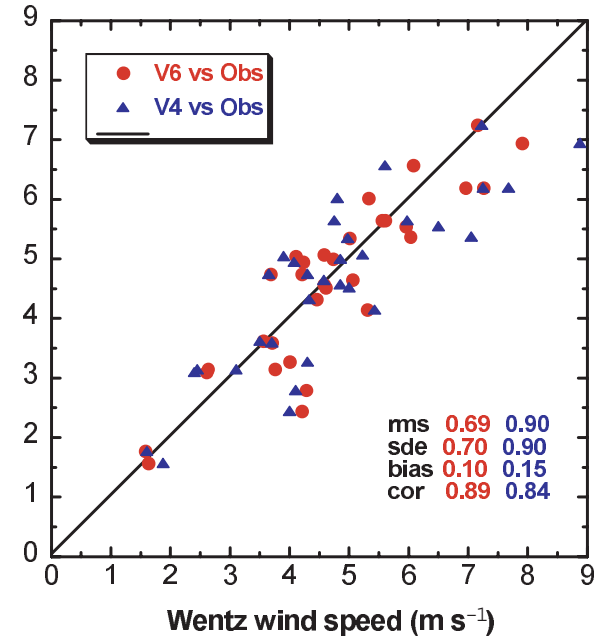

Fig. 1. The respective Wentz Version 6 (red solid circle) and Version 4 (blue solid triangle) (combined F13 and F14) daily surface wind speed vs the Kwajalein Experiment (KWAJEX) observed wind speed, adjusted for the surface, at $9^{0} \mathrm{~N}, 167^{0} \mathrm{E}, 28$ July-11 September 1999.

model were (1) daily mean values of the SSM/I 10-m wind speed $\left(U_{10 m}\right)$ of Wentz $(1997$, version $4-\mathrm{V} 4)$, (2) SSM/I 10-m specific humidity $\left(Q_{10 m}\right)$, (3) 2-m air temperature $\left(T_{2 m}\right)$, (4) SST of NCEP-NCAR reanalysis (referred to as NCEP hereafter), (5) daily SSM/I total $(W),(6)$ the SSM/I bottom-layer (the lowest atmospheric 500-m layer)WB, and (7) the directions of wind stress, taken from those of the surface winds, which are derived from a blend of the Wentz (1997) $\mathrm{SSM} / \mathrm{I} U_{10 m}$, surface wind vectors from ships, buoys, and NCEP following the method of Atlas et al. (1996).
However, there are a few changes/improvements in the input datasets for the GSSTF2b, and a few more for the GSSTF3 production due to a finer resolution $\left(0.25^{\circ} \times 0.25^{\circ}\right)$ requirement. Table 1 summarizes characteristics of input data and parameters used for GSSTF2, GSSTF2b, and GSSTF3, respectively. Detailed descriptions and discussions are presented as follows through this section.

The surface wind speed used in the GSSTF2 production was the Wentz/RSS SSM/I V4 product. Xing (2006) found a linear trend of a $6 \%$ increase in the associated 13.5-year period of wind data. In the latest issued SSM/I V6 product, Wentz indicated that the spurious trends found in the earlier wind speed retrievals were removed. We have performed a validation analysis where a 46-day (i.e., 28 July-11 September 1999) period of daily surface wind speeds from the SSM/I V4 and SSM/I V6 (combined F13 and F14) are compared with the corresponding Kwajalein Experiment (KWAJEX) in situ observed wind speeds, respectively. The analysis shows a promising improvement from SSM/I V4 to SSM/I V6 in all statistical aspects, i.e., correlation coefficient rising from 0.84 to 0.89 ; rootmean-square error dropping significantly from 0.90 to $0.69 \mathrm{~m} \mathrm{~s}^{-1}$; bias reducing from 0.15 to $0.10 \mathrm{~m} \mathrm{~s}^{-1}$ (Fig. 1).

Besides the wind speed, the total precipitable water $(W)$ and bottom-layer precipitable water (WB) would also be replaced by the newly released SSM/I V6 dataset for the production of GSSTF2b (see Table 1) to be consistent. Moreover, the weekly $1^{\circ}$ spatial (latitude-longitude) resolution optimum interpolation (OI) SST version 1 (V1) dataset (Reynolds 
and Smith, 1994) used for GSSTF2 would be replaced by an improved OI SST version 2 (V2) dataset with reduced satellite bias, a new sea ice algorithm, and an improved version of the OI analysis (Reynolds et al., 2002). The revisions result in a modest reduction in the satellite bias that leaves small global residual biases of roughly $-0.03^{\circ} \mathrm{C}$. The major improvement in the V2 analysis occurs at high latitudes due to the new sea ice algorithm where local differences between the old and new analysis can exceed $1^{\circ} \mathrm{C}$. The very recently developed Cross-Calibrated MultiPlatform (CCMP) Ocean Surface Wind Vector product (http://podaac.jpl.nasa.gov/DATA_CATALOG/ ccmpinfo.html), which is based on the same variational analysis method (VAM) applied for producing an earlier surface wind vector dataset (Atlas et al., 1996) used for determining the GSSTF2 wind stress vectors, will be applied for the GSSTF2b and GSSTF3 productions. This new dataset combines data derived from SSM/I, AMSR-E, TRMM TMI, QuikSCAT (Liu et al., 2000) and other missions using VAM to produce a consistent climatological record of ocean surface vector winds at a $25 \mathrm{~km}\left(0.25^{\circ} \times 0.25^{\circ}\right)$ resolution for a period of July 1987-December 2007. There are three CCMP products currently available: (1) Level-2.5 (daily; $25 \mathrm{~km}$ ) contains microwave radiometer (SSM/I, TMI, and AMSR-E) derived wind speed data in swath, supplemented by VAM-derived wind directions. (2) Level-3 (6-hourly; $0.25^{\circ}$ ) contains gridded VAM ocean vector wind fields produced from all of the microwave radiometer data from the Level-2.5 product, blended with scatterometter data (NSCAT and SeaWinds on QuikSCAT/ADEOS2). (3) Level-3.5 (pentad and monthly; $0.25^{\circ}$ ) contains a time-averaged version of the Level-3.0 product. The CCMP Level-2.5 and Level-3 ocean surface wind vector will be applied for the production of GSSTF2b and GSSTF3, respectively.

The second phase product GSSTF3 has been planned for production with a finer resolution of $0.25^{\circ} \times 0.25^{\circ}$. The weekly $1^{\circ}$ (latitude-longitude) OI (V1/V2) SST reanalysis used for producing GSSTF2/GSSTF2b is too coarse to apply to GSSTF3. Moreover, the OI SST based on the traditional NOAA/Advanced Very High Resolution Radiometer (AVHRR) cannot resolve diurnal variations or provide values in cloudy conditions (Curry et al., 2004). As a result, the OI SST tends to be biased to fair weather. In order to improve the fair-weather bias and accommodate the finer resolutions in both space and time, the twice-daily (one descending, one ascending) SST from TRMM/TMI (Wentz version-4 product, December 1997 to present) and AMSR-E (Wentz version 5 products, June 2002 to present), along with ocean surface wind vectors obtained from the aforementioned CCMP Level-3 product from July 1987 through December 2007, are thus planned for utilization in the GSSTF3 production (see Tables 1 and 2). The TMI radiometer is well-calibrated and contains lower frequency channels (e.g., $10.7 \mathrm{GHz}$ with a very small attenuation due to cloud penetrating), which are required for obtaining a more complete picture of sea surface temperatures than retrieved by infrared (Wentz et al., 2002). The TRMM/TMI version-4 SST data are provided by RSS (http://www.ssmi.com) as daily maps (divided into ascending and descending orbit segments) from December 1997 to the present. The TMI images cover a global region extending from $40^{\circ} \mathrm{S}$ to $40^{\circ} \mathrm{N}$ due to the TRMM semi-equatorial and lowinclination orbit (i.e., an inclination of 35 degrees to the Equator) at a pixel resolution of 0.25 degrees. A root mean square error of about $0.6^{\circ}$ found between the TMI SSTs and the ocean buoy measurements from December 1997 to June 1999 was partially attributed to the satellite-buoy spatial-temporal sampling mismatch and the difference between the ocean skin temperature and bulk temperature (Wentz et al., 2002). The local times of data collection change progressively, i.e., about 0.033 hour earlier at each equatorial crossing (Negri et al., 2002) for any given earth location between $40^{\circ} \mathrm{S}$ and $40^{\circ} \mathrm{N}$ as the TRMM satellite travels west to east precessing with respect to the Sun.

The AMSR-E sensor, which was launched on May 4, 2002 onboard NASA's Aqua spacecraft, provides an uninterrupted view of the global SSTs due to a key feature of being capable of seeing through clouds. In addition to the TMI SSTs, the daily gridded $\left(0.25^{\circ} \times\right.$ $0.25^{\circ}$ ) AMSR-E SST (version-5) recently issued by RSS (http://www.ssmi.com) will also be used for the GSSTF3 production. The geophysical SST data consist of orbit data that are mapped to a 0.25 degree grid and divided into two maps depending on ascending (local daytime) and descending (local nighttime) passes. There are two special improvements in this upgraded version-5 product compared to its version4 counterpart worth our attention. First, the latitudes and longitudes for the geophysical retrievals are now more accurate thanks to the improved geolocation routines. Secondly, the data latency is reduced relative to the version- 4 product since the near-real time bytemaps and imagery, normally about three hours behind the observations, are now available for the version-5 product. In summary, three OI (using the scheme by Reynolds and Smith, 1994) microwave (MW) SST products are created at a $0.25^{\circ} \times 0.25^{\circ}$ resolution by RSS based on the aforementioned TMI and AMSR-E SSTs. The OI TMI SSTs (ranging from $40^{\circ} \mathrm{S}$ to $40^{\circ} \mathrm{N}$ ) are available from January 1998 to 
(a)

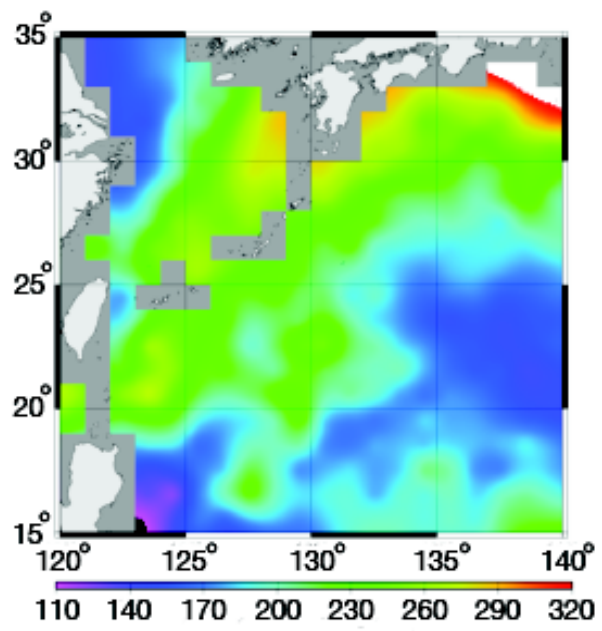

(b)

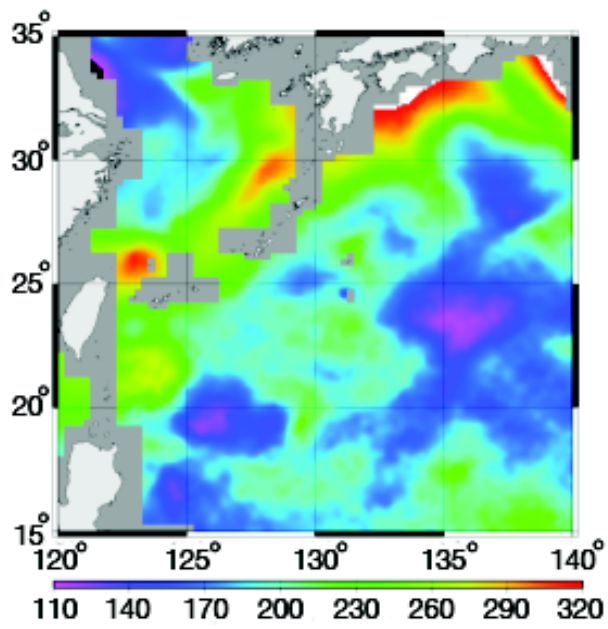

Fig. 2. The simulated GSSTF surface latent heat flux $\left(\mathrm{W} \mathrm{m}^{-2}\right)$ in December 2000 (monthly average) at the Kuroshio region of (a) $1^{\circ} \times 1^{\circ}$ (current GSSTF2) based on the NCEP 7 day average SST (composite using cloud-limiting AVHRR), and (b) $0.25^{\circ} \times 0.25^{\circ}$ (proposed GSSTF3) using cloud-penetrating TRMM/TMI and AMSR-E

the present, while the OI AMSR-E SSTs are available globally from June 2002 to the present. The third product [OI TMI+AMSR-E SSTs] consisting of the combined OI SSTs (blending the data from TMI and AMSR-E) are available globally from June 2002 to the present. These OI MW SSTs are found to accurately resolve real SSTs even though they differ from the smoothed-out NCEP OI (Reynolds and Smith, 1994) SSTs of low resolution. A higher standard deviation has, however, been found when latitudes greater than 40-degree are included. The more frequently occurring dynamic SST features (such as the western boundary currents) at higher latitudes are suspected to play a role in the increased discrepancy. The OI MW SSTs may be further improved through better error specification, inclusion of more data from other satellites/sensors, as well as extended research in modeling diurnal warming. More details can be found on the RSS website http://www.ssmi.com.

There exists practical difficulty in using the current GSSTF2 dataset with a $1^{\circ} \times 1^{\circ}$ resolution for a handful of studies involving finer scale air-sea interaction processes, such as investigations of the typhoon-induced SST cooling (Lin et al., 2003a,b), and the Kuroshio current associated air-sea interaction processes. Furthermore, the SST used for deriving the GSSTF2 dataset was based on the satellite thermal infrared measurement (i.e., Reynolds et al., 2002), which was biased towards fair-weather.
Lin et al. ${ }^{\mathrm{a}}$ also suggested the possibility of deriving finer-resolution air-sea flux data (i.e. $0.25^{\circ} \times 0.25^{\circ}$ ) using SSTs of cloud-penetrating measurements from TRMM/TMI and AMSR-E, and ocean surface wind vectors from QuikSCAT. They were able to identify a clear typhoon-induced cooling (i.e., SST as low as $23^{\circ} \mathrm{C}-24^{\circ} \mathrm{C}$ ), which occurred at $19^{\circ}-21^{\circ} \mathrm{N}, 118^{\circ}-120^{\circ} \mathrm{E}$ due to the passing of Typhoon Kai-Tak on 9 July 2000, by applying the SST of $0.25^{\circ} \times 0.25^{\circ}$, but indistinguishable in the SST of $1^{\circ} \times 1^{\circ}$ (a measured SST using cloudlimiting AVHRR). As expected, an improved preliminary GSSTF surface flux estimate was further produced with a finer spatial resolution. Figure 2 clearly demonstrates a genuine improvement in the surface latent heat flux in December 2000 (monthly average) in the Kuroshio region with the spatial resolution being upgraded from a $1^{\circ} \times 1^{\circ}$ (Fig. 2 a) to a $0.25^{\circ} \times 0.25^{\circ}$ (Fig. 2b).

\section{Productions of GSSTF2b (first-phase) and GSSTF3 (second-phase)}

Similar to the GSSTF2 products, the GSSTF2b dataset (the first-phase output) would provide daily, monthly, and monthly climatology of a $1^{\circ} \times 1^{\circ}$ gridded global $\left(90^{\circ} \mathrm{N}\right.$ to $\left.90^{\circ} \mathrm{S}\right)$ ocean surface latent heat flux, sensible heat flux, zonal and meridional wind stresses, surface (10-m) air specific humidity, lowest 500-m precipitable water, 10-m wind speed, and sea-air humidity

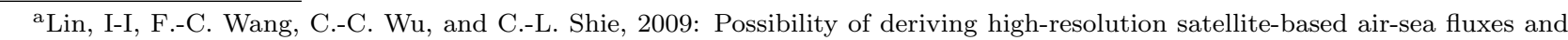
its validation. (submitted to Geophys. Res. Lett.) 
Table 2. Characteristics of satellite input data for GSSTF3.

\begin{tabular}{|c|c|c|c|c|}
\hline Datasets & $\begin{array}{l}\text { Time length } \\
\text { (Month/year) }\end{array}$ & Spatial sample & Data domain & Data Frequency \\
\hline $\begin{array}{l}\text { OI TRMM/TMI } \\
\text { SST (RSS) }\end{array}$ & 01/98-present & $\begin{array}{l}\text { pixel resolution of } 0.25 \text { degree } \\
\text { of } 0.25 \text { degree }\end{array}$ & $40^{\circ} \mathrm{N}-40^{\circ} \mathrm{S}$ & Twice daily \\
\hline $\begin{array}{l}\text { OI AMSR-E } \\
\text { SST (RSS) }\end{array}$ & 06/02 - present & $\begin{array}{l}\text { pixel resolution } \\
\text { of } 0.25 \text { degree }\end{array}$ & $90^{\circ} \mathrm{N}-90^{\circ} \mathrm{S}$ & Twice daily \\
\hline $\begin{array}{l}\text { OI TMI+AMSR-E } \\
\text { SST (RSS) }\end{array}$ & 06/02-present & $\begin{array}{l}\text { pixel resolution } \\
\text { of } 0.25 \text { degree }\end{array}$ & $90^{\circ} \mathrm{N}-90^{\circ} \mathrm{S}$ & Daily \\
\hline $\begin{array}{l}\text { QuikSCAT } \\
\text { Wind direction } \\
\text { (CCMP Level-3) }\end{array}$ & 07/99-present & $\begin{array}{l}\text { pixel resolution } \\
\text { of } 0.25 \mathrm{~km}\end{array}$ & $\begin{array}{c}90^{\circ} \mathrm{N}-90^{\circ} \mathrm{S} \\
(90 \% \text { ice free ocean })\end{array}$ & $\begin{array}{l}\text { Twice daily } \\
\text { (binned from } \\
\text { 6-hourly) }\end{array}$ \\
\hline $\begin{array}{l}\text { ADEOS2-SeaWinds } \\
\text { Wind direction } \\
\text { (CCMP Level-3) }\end{array}$ & $04 / 03-10 / 03$ & $\begin{array}{l}\text { pixel resolution } \\
\text { of } 0.25 \text { degree }\end{array}$ & $\begin{array}{c}90^{\circ} \mathrm{N}-90^{\circ} \mathrm{S} \\
(90 \% \text { ice free ocean })\end{array}$ & $\begin{array}{l}\text { Twice daily } \\
\text { (binned from } \\
\text { 6-hourly) }\end{array}$ \\
\hline
\end{tabular}

difference, but with a 8-year longer period than that of GSSTF2, i.e., July 1987 to December 2008. The GSSTF3 dataset (second-phase output) would include the same kind of output datasets as those of GSSTF2b except with a finer spatial resolution $\left(0.25^{\circ} \times 0.25^{\circ}\right)$, a 12 -h (instead of daily) temporal resolution, a shorter time period (July 1999-December 2009), and likely with a smaller "global" domain (less than $90^{\circ} \mathrm{N}-90^{\circ} \mathrm{S}$ due to the limited spatial coverage of the new input satellite data, see Table 2).

Currently, we are in the process of massively producing the first-phase $1^{\circ} \times 1^{\circ}$ GSSTF2b dataset that are expected to be completed soon. We are also currently developing/testing a revised setup of transfer coefficients applied in the bulk flux model/algorithm to accommodate strong wind conditions (particularly for hurricane/typhoon-ocean interaction study). The revised model will soon be used for the production of the second-phase $0.25^{\circ} \times 0.25^{\circ}$ GSSTF3 dataset. The newly improved and available input datasets [i.e., the SSM/I V6 products (wind speed, total precipitable water, and brightness temperatures) and the NCEP SST (V2)], along with the 2-m air temperature, the sea level pressure of NCEP-NCAR reanalysis, and the CCMP Level-2.5 surface wind vectors are currently under processing for grid data of $1^{\circ} \times 1^{\circ}$. The model used for a $1^{\circ} \times 1^{\circ}$ production (GSSTF2b) will also be upgraded to accommodate a finer grid of a $0.25^{\circ} \times 0.25^{\circ}$ for the second-phase production of GSSTF3. In addition to the aforementioned SSM/I V6 input parameters, the SST from AMSR-E and TMI, and the CCMP Level-3 ocean surface wind vector will be processed for a finer grid of $0.25^{\circ} \times 0.25^{\circ}$ for producing GSSTF3. Both GSSTF2b and GSSTF3 will be validated with field data, and compared with other datasets (e.g., GSSTF2, HOAPS2, J-OFURO, and NCEP reanalysis), respectively, before their official release. These long-term, satellite-based GSSTF2b
(July 1987-December 2008) and GSSTF3 (July 1999December 2009) products are scheduled to be completed and released for the research community to use via GSFC/DISC by late 2009 and early 2011, respectively. They will eventually replace the current GSSTF2 (July 1987-December 2000) dataset with extensive and improved global ocean surface fluxes (latent heat flux, sensible heat flux, and wind stress). We believe that these improved products of GSSTF $2 b$ and GSSTF3 will continue to be useful for diagnosing the global water and energy cycles, and hence better understand how the global evaporation, precipitation, water, and energy change periodically (e.g., seasonally and annually), and ultimately understand how the Earth's climate changes. The GSSTF2b product with daily temporal and a one degree spatial resolution can be used to examine and validate climate variability at these scales. On the other hand, the GSSTF3 product with 12-h temporal and a quarter degree spatial resolution would be useful for studying the hurricaneocean interaction of higher-frequency and finer-scale scenarios. Fully tested, we believe that these products can further serve as a crucial input for data assimilation of oceanic GCMs for forecasting. We will also continually distribute the new products GSSTF2b and GSSTF3 to the SEAFLUX project, established by the WCRP/GEWEX Radiation Panel.

Acknowledgements. The first author would like to particularly dedicate this note, which introduces reviving the production of the GSSTF datasets, to his mentor: the late research scientist Dr. S.-H. Chou (aka Sue). Without her genuine intelligence, intuition, great vision, and perseverance, the productions of GSSTF1 and GSSTF2 would have not been possible. This study is supported by the Making Earth System data records for Use in Research Environments (MEaSUREs) Program of NASA Science Mission Directorate-Earth Science Division. The first author is 
especially grateful to M. Maiden, the MEaSUREs Program Manager, for her support of this research.

\section{REFERENCES}

Andreas, E. L., 1992: Sea spray and the turbulent air-sea heat fluxes. J. Geophys. Res., 97, 11429-11441.

Andreas, E. L., J. B. Edson, E. C. Monahan, M. P. Rouault, and S. D. Smith, 1995: The spray contribution to net evaporation from the sea: A review of recent progress. Bound.-Layer Meteor., 72, 3-52.

Atlas, R., R. N. Hoffman, S. C. Bloom, J. C. Jusem, and J. Ardizzone, 1996: A multiyear global surface wind velocity dataset using SSM/I wind observations. Bull. Amer. Meteor. Soc., 77, 869-882.

Black, P. G., E. A. D'Asaro, W. M. Drennan, J. R. French, P. P. Niiler, T. B. Sanford, E. J. Terrill, E. J. Walsh, and J. A. Zhang, 2007: Air-sea exchanges in hurricanes. Bull. Amer. Meteor. Soc., 88, 357-374.

Brunke, M. A., C. W. Fairall, X. Zeng, L. Eymard, and J. A. Curry, 2003: Which bulk aerodynamic algorithms are least problematic in computing ocean surface turbulent fluxes? J. Climate, 16, 619-635.

Bourras, D., 2005: Comparison of five satellite derived latent heat flux products to moored buoy data. N.A.I. (Notes of IPSL Instrumental Activities), 15pp.

Bourras, D., L. Eymard, and W. T. Liu, 2002: A neural network to estimate the latent heat flux over oceans from satellite observations. Int. J. Remote Sens., 23, 2405-2423.

Chiu, L. S., and Y. Xing, 2004: Modes of interannual variability of oceanic evaporation observed from GSSTF2, Gayana: International Journal of Biodiversity, Oceanology and Conservation, 68(2), 115120.

Chou, S.-H., 1993: A comparison of airborne eddy correlation and bulk aerodynamic methods for ocean-air turbulent fluxes during cold-air outbreaks. Bound.Layer Meteor., 64, 75-100.

Chou, S.-H., R. M. Atlas, C-L. Shie. and J. Ardizzone, 1995: Estimates of surface humidity and latent heat fluxes over oceans from SSM/I data. Mon. Wea. Rev., 123, 2405-2425.

Chou, S.-H., C.-L. Shie, R. M. Atlas, and J. Ardizzone, 1997: Air-sea fluxes retrieved from special sensor microwave imager data. J. Geophys. Res., 102, 1270512726 .

Chou, S.-H., C.-L. Shie, R. Atlas, and J. Ardizzone, 2000: The Goddard Satellite-Based Surface Turbulent Fluxes Dataset-Version 1 (GSSTF 1.0) [global (grid of $2^{\circ} \times 2.5^{\circ}$ ) daily air-sea surface fluxes from July 1987 to December 1994]. [Available online at http://disc.sci.gsfc.nasa.gov/precipitation/ gsstf1.0.shtml.]

Chou, S.-H., E. Nelkin, J. Ardizzone, R. Atlas, and C.L. Shie, 2001: The Goddard Satellite-Based Surface Turbulent Fluxes Dataset-Version 2 (GSSTF 2.0) [global (grid of $1^{\circ} \times 1^{\circ}$ ) daily air-sea surface fluxes from July 1987 to December 2000]. [Available online at http://disc.gsfc.nasa.gov/precipitation/ gsstf2.0.shtml.]

Chou, S.-H., E. Nelkin, J. Ardizzone, R. M. Atlas, and C.-L. Shie, 2003: Surface turbulent heat and momentum fluxes over global oceans based on the Goddard satellite retrieval, version 2 (GSSTF2). J. Climate, 16, 3256-3273.

Chou, S.-H., E. Nelkin, J. Ardizzone, and R. Atlas, 2004: A comparison of latent heat fluxes over global oceans for four flux products, J. Climate, 17, 3973-3989.

Curry, J. A., and Coauthors, 1999: High-resolution satellite-derived dataset of the surface fluxes of heat, freshwater, and momentum for the TOGA COARE IOP. Bull. Amer. Meteor. Soc., 80, 2059-2080.

Curry, J. A. and Coauthors, 2004: SEAFLUX, Bull. Amer. Meteor. Soc., 85(3), 424.

da Silva, A., C. C. Young, and S. Levitus, 1994: Algorithms and Procedures. Vol. 1, Atlas of Surface Marine Data 1994, NOAA Atlas NESDIS 6, 83pp.

Donelan, M. A., B. K. Haus, N. Reul, W. J. Plant, M. Stiassnie, H. C. Graber, O. B. Brown, and E. S. Saltzman, 2004: On the limiting aerodynamic roughness of the ocean in very strong winds. Geophys. Res. Lett., 31, L18306.

Emanuel, K. A., 1999: Thermodynamic control of hurricane intensity. Nature, 401, 665-669.

Fairall, C. W., E. F. Bradley, D. P. Rogers, J. B. Edson, and G. S. Young, 1996: Bulk parameterization of air-sea fluxes for Tropical Ocean Global Atmosphere Coupled Ocean-Atmosphere Response Experiment. J. Geophys. Res., 101(C2), 3747-3764.

Fairall, C. W., E. F. Bradley, J. E. Hare, A. A. Grachev, and J. B. Edson, 2003: Bulk parameterization of airsea fluxes: Updates and verification for the COARE algorithm. J. Climate, 16, 571-591.

Jones, C., P. Peterson, and C. Gautier, 1999: A new method for deriving ocean surface specific humidity and air temperature: an artificial neural network approach. J. Appl. Meteor., 38, 1229-1246.

Josey, S. A., E. C. Kent, and P. K. Taylor, 1999: New insights into the ocean heat budget closure problem from analysis of the SOC air-sea flux climatology. $J$. Climate, 12, 2856-2880.

Kalnay, E., and Coauthors, 1996: The NCEP/NCAR 40Year Reanalysis Project. Bull. Amer. Meteor. Soc., 77, 437-471.

Kanamitsu, M., W. Ebisuzaki, J Woollen, S.-K. Yang, J. J. Hnilo, M. Fiorino, and G. L. Potter, 2002: NCEPDOE AMIP-II Reanalysis (R-2). Bull. Amer. Meteor. Soc., 83, 1631-1643.

Kubota, M., K. Ichikawa, N. Iwasaka, S. Kizu, M. Konda, and K. Kutsuwada, 2002: Japanese Ocean Flux Data Sets with Use of Remote Sensing Observations (JOFURO). J. Oceanogr., 58, 213-215.

Lin, I-I, W. T. Liu, C.-C. Wu, J. C. H. Chiang, and C.-H. Sui, 2003a: Satellite observations of modulation of surface winds by typhoon-induced upper ocean cooling. Geophys. Res. Lett., 30(3), 1131, doi: 10.1029/2002GL015674, 
Lin, I-I, and Coauthors, 2003b: New evidence for enhanced ocean primary production triggered by tropical cyclone. Geophys. Res. Lett., 30(13), 1718, doi: 10.1029/2003GL017141.

Liu, W. T., K. B. Katsaros, and J. A. Businger, 1979: Bulk parameterization of air-sea exchanges of heat and water vapor including the molecular constraints at the interface. J. Atmos. Sci., 36, 1722-1735.

Liu, W. T., X. Xie, P. S. Polito, S. P. Xie, and H. Hashizume, 2000: Atmospheric manifestation of tropical instability wave observed by QuikSCAT and Tropical Rainfall Measuring Mission. Geophys. Res. Lett., 27(16), 2545-2548.

Negri, A. J., T. L. Bell, and L. Xu, 2002: Sampling of diurnal cycle of precipitation using TRMM. J. Atmos. Oceanic Technol., 19, 1333-1344.

Powell, M. D. P. J. Vickery, and T. A. Reinhold, 2003: Reduced drag coefficient for high wind speeds in tropical cyclones. Nature, 422, 279-283.

Renfrew, I. A., G. W. K. Moore, P. S. Guest, and K. Bumke, 2002: A comparison of surface layer and surface turbulent flux observations over the Labrador Sea with ECMWF analyses and NCEP reanalyses. J. Phys. Oceanogr., 32, 383-400.

Reynolds, R. W., and T. S. Smith, 1994: Improved global sea surface temperature analyses. J. Climate, 7, 929-948.

Reynolds, W. R., N. A. Rayner, T. M. Smoth, D. C. Stokes, and W. Wang, 2002: An improved in situ and satellite SST analysis for climate. J. Climate,
15, 1609-1625.

Schulz, J., J. Meywerk, S. Ewald, and P. Schluessel, 1997: Evaluation of satellite-derived latent heat fluxes. $J$. Climate, 10, 2782-2795.

Wang, W., and M. J. McPhaden, 2001: What is the mean seasonal cycle of surface heat flux in the equatorial Pacific? J. Geophys. Res., 106, 837-857.

Wentz, F. J., 1997: A well calibrated ocean algorithm for SSM/I. J. Geophys. Res., 102, 8703-8718.

Wentz, F. J., C. Gentemann, D. Smith, and D. Chelton, 2000: Satellite measurements of sea surface temperature through clouds. Science, 288, 847-850.

Woodruff, S. D., S. J. Lubker, K. Wolter, S. J. Worley, and J. D. Elm, 1993: Comprehensive OceanAtmosphere Data Set (COADS) release la: 1980-92. Earth System Monitor, 4, 4-8.

Xie, P., J. E. Janowiak, M. Chen, C.-L. Shie, and L. Chiu, 2007: Seasonal and interannual variations of fresh water flux over global oceans in the NCEP CDAS, CDAS2, GDAS, GFS, and CFS. Assessing and Exploiting Re-analysis Data Sets, IUGG 2007, 2-13 July 2007, Perugia, Italy.

Xing, Y. K., 2006: Recent changes in oceanic latent heat flux from remote sensing. $\mathrm{Ph}$. D. dissertation, School of Computational Science, George Mason University, Fairfax VA 22030, 119pp.

Zeng, X., M. Zhao, and R. E. Dickinson, 1998: Intercomparison of bulk aerodynamic algorithms for the computation of sea surface fluxes using TOGA COARE and TAO data. J. Climate, 11, 2628-2644. 